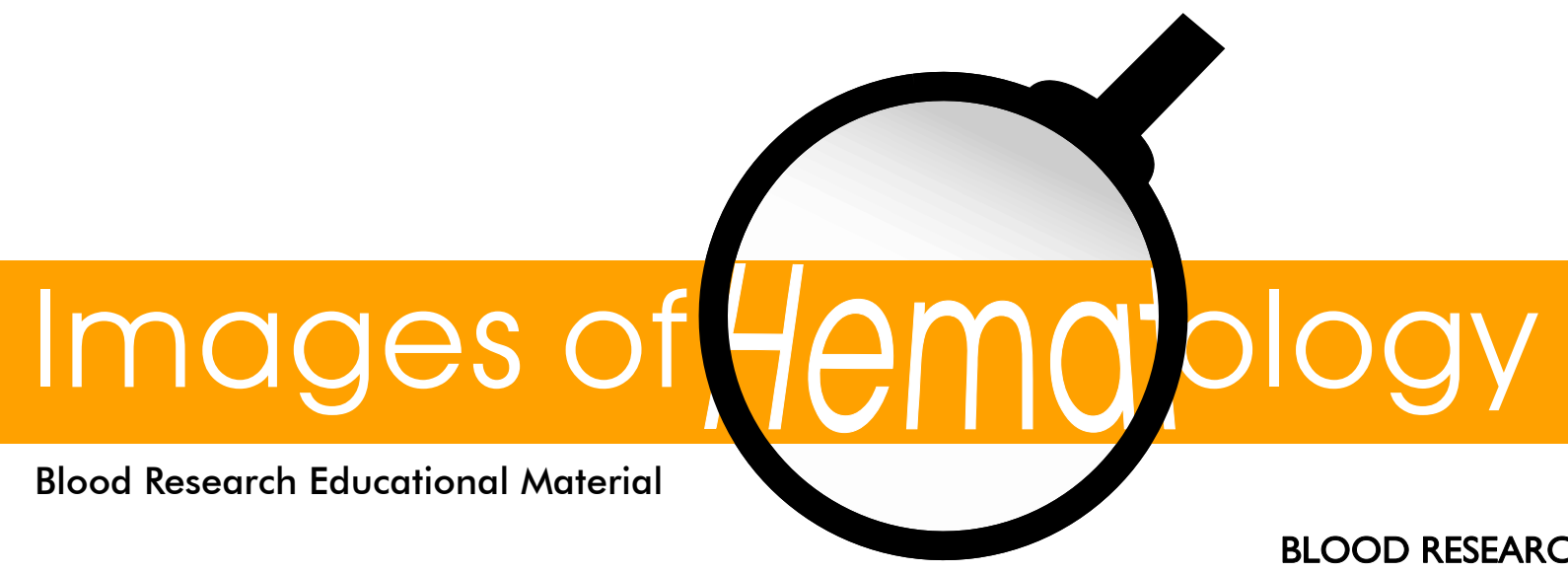

Volume $56 \cdot$ Number $3 \cdot$ September 2021

https://doi.org/10.5045/br.2021.2021051

\title{
Plasma cells in disguise: the masquerader in hematopathology
}

\author{
Richa Juneja ${ }^{1}$, Karthika Kundil Veetil ${ }^{2}$, Haraprasad Pati ${ }^{2}$ \\ ${ }^{1}$ Department of Pathology, All India Institute of Medical Science, Nagpur, ${ }^{2}$ Department of Hematology, All India Institute of \\ Medical Science, New Delhi, India
}

Received on March 4, 2021; Revised on April 5, 2021; Accepted on July 8, 2021

Correspondence to Richa Juneja, D.M., Department of Pathology, All India Institute of Medical Science, 309, Near VMV College, Wardhman Nagar, Nagpur 440008, India, E-mail: drrichajuneja@gmail.com
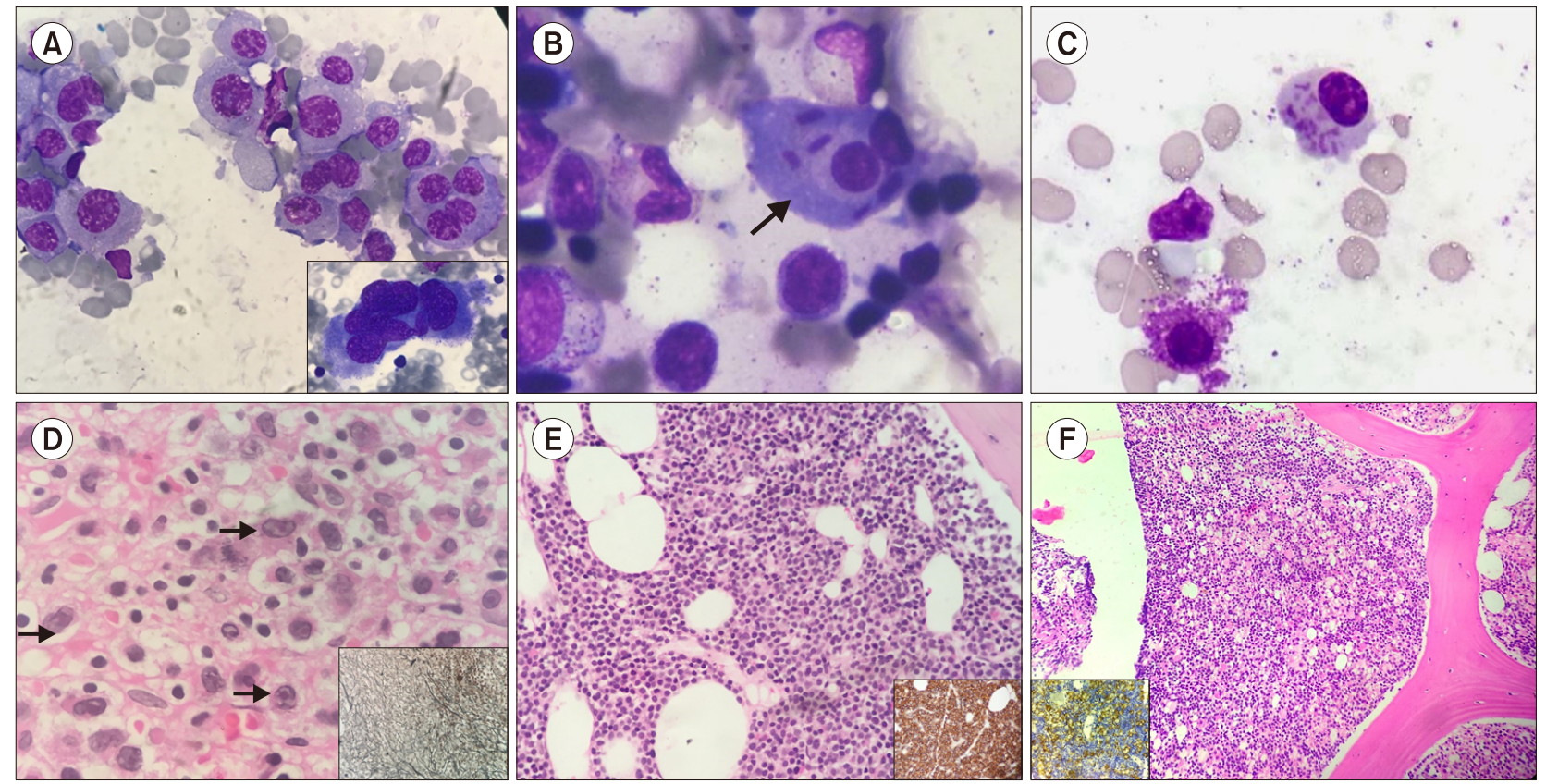

Six challenging morphological variants of plasma cells were identified in various plasma cell neoplasm and confirmed with flow cytometric immunophenotyping or immunohistochemistry. (A) Multinucleated plasma cells, with few resembling a megakaryocyte, in Jenner-Giemsa-stained bone marrow aspirate in an "anaplastic variant" of myeloma $(\times 40)$. Inset shows a bizarre plasma cell $(\times 100)$. Classical binucleate plasma cell with thick rod-like inclusion in a smear $(\mathrm{B}, \times 100)$. A case of MGUS with intracytoplasmic coarse azurophilic Snapper-Schneid granules in plasma cells $(\mathrm{C}, \times 100)$. In a case with a dry tap, bone marrow biopsy specimen shows large plasma cells with moderate cytoplasm, irregular nuclei with chromatin remodeling and prominent nucleoli (arrow) in a dense fibrotic marrow. Positive staining for CD138 and kappa restriction confirmed a diagnosis of plasmablastic myeloma (D, $\times 40)$. Bone marrow biopsy revealed sheet-like arrangement of small cells with scanty cytoplasm that mimic a lymphoma in a "small cell variant" $(\mathrm{E}, \times 20)$; inset shows CD138-positive staining of all cells with aberrant CD20 positivity and CD45 negativity; FISH showed $\mathrm{t}(11: 14)$. Bone marrow biopsy specimen showed a histiocytic variant of large plasma cells with abundant pale cytoplasm among classical small lymphoid cells in lymphoplasmacytic lymphoma $(\times 20)$; inset shows CD138 positivity and lambda restriction (F). 